Case Series

\title{
Management of tibial plateau fractures with compromised soft tissue using hybrid external fixator
}

\author{
Mahesh K. Sharma, Mukul Jain, Harish K. Jain*, Sukhveer Khichar, Rahul Jadoo
}

Department of Orthopaedics, Jhalawar Medical College and SRG Hospital, Jhalawar, Rajasthan, India

Received: 04 August 2020

Revised: 19 September 2020

Accepted: 25 September 2020

\author{
*Correspondence: \\ Dr. Harish K. Jain, \\ E-mail: drhkjain99@gmail.com
}

Copyright: ( $)$ the author(s), publisher and licensee Medip Academy. This is an open-access article distributed under the terms of the Creative Commons Attribution Non-Commercial License, which permits unrestricted non-commercial use, distribution, and reproduction in any medium, provided the original work is properly cited.

\begin{abstract}
Tibial plateau fractures with high energy trauma are complex injury due to its precarious soft tissue envelope. High energy trauma has high incidence of open fractures, articular depression, fracture comminution and displacement, soft tissue injury, and neurovascular compression. It is often difficult to achieve and maintain reduction and commonly predisposes to secondary arthritis. Hybrid external fixator minimizes the iatrogenic soft tissue damage, provides adequate fixation of the fracture, permits early range of motion, easy wound care and leave no large implant in subcutaneous position. This study was performed to evaluate the functional and radiological outcome with this procedure. In this case series, prospective study of 15 cases of tibial plateau fractures were treated with hybrid external fixator at tertiary care teaching hospital in southern Rajasthan from July 2018 to June 2019. The functional and radiological outcome was assessed by Rasmussen functional and radiological score. The mean interval between surgery and union was 16 weeks (range 13 to 18 weeks). Rasmussen functional results were acceptable in 13 cases $(86.66 \%)$ comprising excellent in $9(60 \%)$, good in $4(26.66 \%)$, and fair in $2(13.33 \%)$. Rasmussen radiological results were acceptable in 13 cases $(86.66 \%)$ comprising excellent in $9(60 \%)$, good in 4 (26.66\%), and fair in $2(13.33 \%)$. Minimal internal and hybrid external fixation for management of tibial plateau fracture with compromised soft tissue is more biological, require less surgical time, less hospital stay, very effective in compromised soft tissue, highly cost effective and has minimal complications with good functional outcome.
\end{abstract}

Keywords: Tibial plateau fracture, Hybrid fixator, Schatzker, External fixator, Rasmussen score

\section{INTRODUCTION}

Motor vehicle accident, fall from height, automobile bumper impact and sports injury are common causes of tibial plateau fracture. Mechanism of injury is axial loading with varus or valgus stress.

Tibial plateau fractures with high energy trauma are complex injury due to its precarious soft tissue envelope. The status of soft tissue envelop mirrors the amount of energy imparted to the bone. High energy trauma has high incidence of open fractures, articular depression, fracture comminution and displacement, soft tissue injury, and neurovascular compression.
The comminution at metaphyseal region and articular surface makes anatomical reduction difficult and compromised soft tissue makes use implant inside more vulnerable to infection Incongruity of articular surface leads to early secondary osteoarthrosis.

The goals of treatment of tibial plateau fracture are to minimize further injury to an already traumatized soft tissue envelop of proximal tibia, reconstruction of proximal tibial articular surface, restore limb axial alignment, achieve stable relationship between metaphysis and diaphysis and pain free non osteoarthritic knee with good range of motion. Inadequate treatment of these 
fractures may result in long term pain, instability, deformity, stiffness, arthritis.

Controversy and debate continue to surround the management of this fracture due to high rate of complications irrespective of mode of treatment. Management strategies of proximal one fourth leg bone fractures are traction and cast immobilization, external fixation, open reduction and internal fixation with single or dual plating, staged management initially by external fixation and later on definitive internal fixation, minimal invasive technique e.g. cannulated cancellous screws and hybrid external fixation and arthroscopic assisted minimally invasive internal fixation with external fixation.

Hybrid external fixator minimizes the iatrogenic soft tissue damage and its associated risks, provides adequate fixation of the fracture, permits early range of motion, easy wound care and leave no large implant in subcutaneous position. ${ }^{1,2}$ It is also less technically demanding, can be done in average orthopaedic setup and more cost effective. ${ }^{3}$ These advantages have led to the increased use of hybrid external fixator for tibial plateau fracture with compromised soft tissue.

Keeping in view the promising results reported by various authors with the use of minimal internal and hybrid external fixation for tibial plateau fracture with compromised soft tissue; this case series has been undertaken to evaluate the functional and radiological outcome with this procedure.

\section{CASE SERIES}

\section{Case 1}

A 42 year male with open Gustilo Anderson type 3A metaphyseal proximal tibia fracture suffered in road traffic accident (RTA) was fixed with hybrid ring fixator and achieved radiological union in 12 weeks with excellent result.

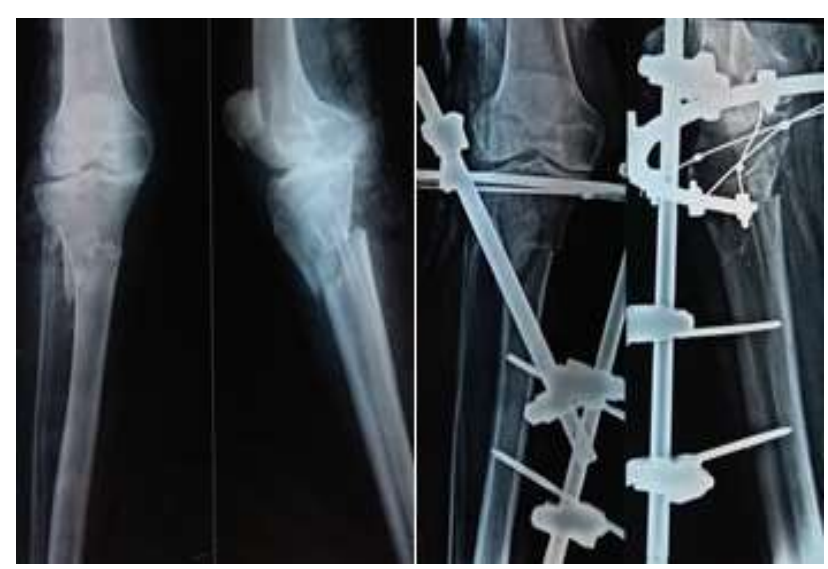

Figure 1: Comminuted proximal tibia fracture stabilised by hybrid external fixator.

\section{Case 2}

A 48 year male suffered open type $3 \mathrm{~A}$ and type VI schatzker fracture in RTA which was fixed and united in 15 weeks. Patient had fair results as he required gastrocnemius flap and had knee stiffness complication.

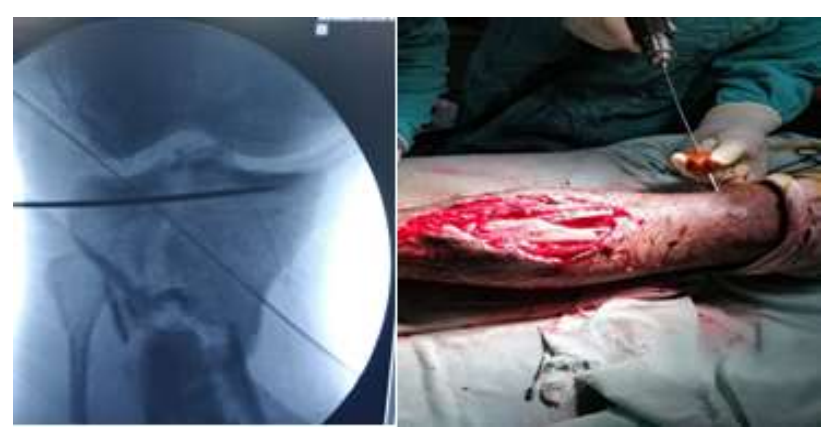

Figure 2: Open fracture proximal tibia with shaft extension managed with fixator.

Case 3

A 30 year female had type I schatzker fracture in RTA which united in 14 weeks with excellent results.

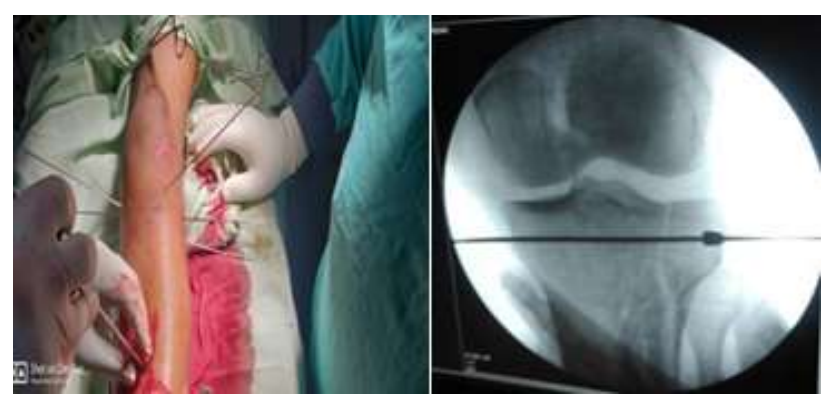

Figure 3: Isolated lateral condyle fracture fixed with hybrid fixator.

\section{Case 4}

A 62 year male had open type 2, metaphyseal fracture in RTA which united in 14 weeks and had excellent results.

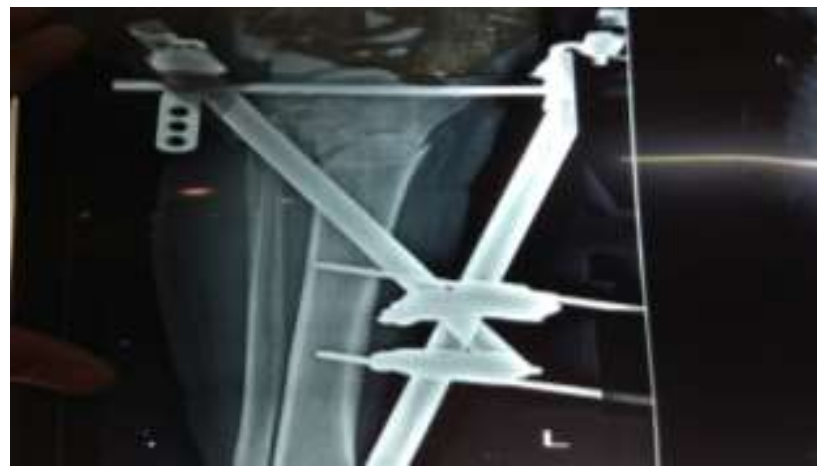

Figure 4: Open type 2 metaphyseal fracture with hybrid external fixator. 


\section{Case 5}

A 50 year male had a close metaphyseal proximal tibia fracture due to fall on ground which had achieved excellent results with union in 12 weeks.

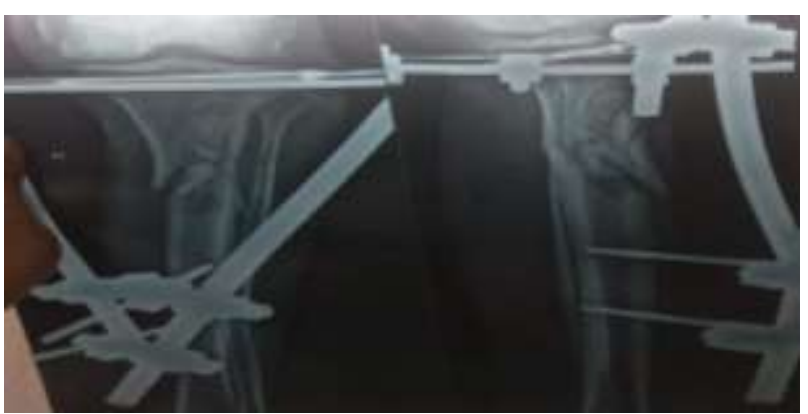

Figure 5: Closed metaphyseal fracture treated with hybrid external fixator.

\section{Case 6}

A 59 year male had type 1 open and type VI schatzker fracture due to assault which united well in 13 weeks with bone marrow infusion and had excellent results thereafter.

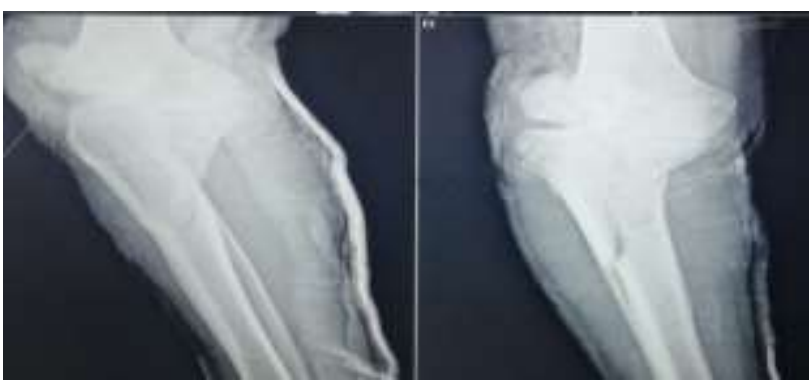

Figure 6: Lateral condyle fracture with extension upto shaft.

\section{Case 7}

A 45 year female had open type 2 and segmental tibia fracture had good results with union in 14 weeks and had complication of pin tract infection which was cured after fixator removal and antibiotics.

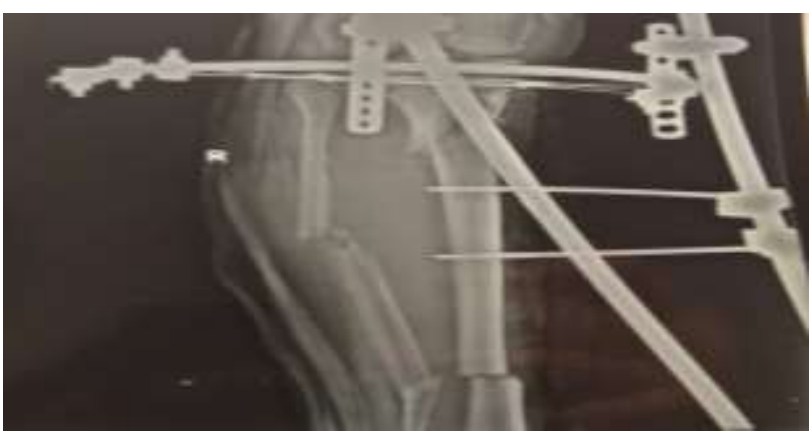

Figure 7: Segmental tibia fracture with hybrid external fixator.
Case 8

A 25 year male had type I open and type II schatzker fracture in RTA which united with excellent results in 12 weeks.

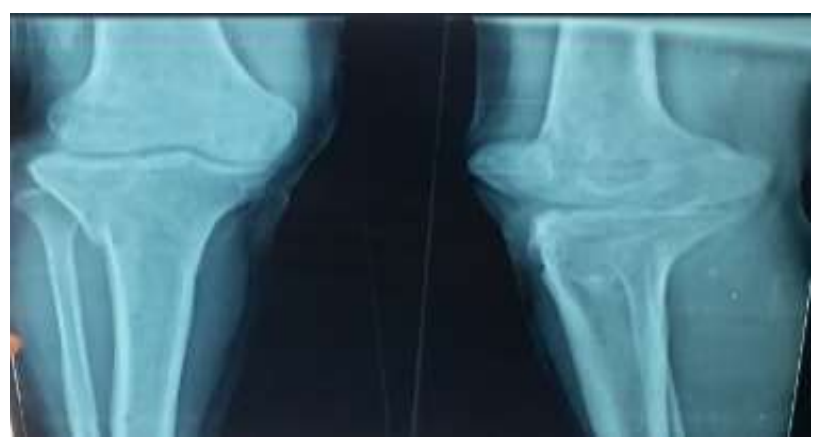

Figure 8: Split and depressed lateral condyle fracture managed with fixator.

\section{Case 9}

A 40 year male had type 2 open and type VI schatzker fracture with segmental tibia fracture in RTA which had united in 13 weeks with fair results due to knee stiffness.

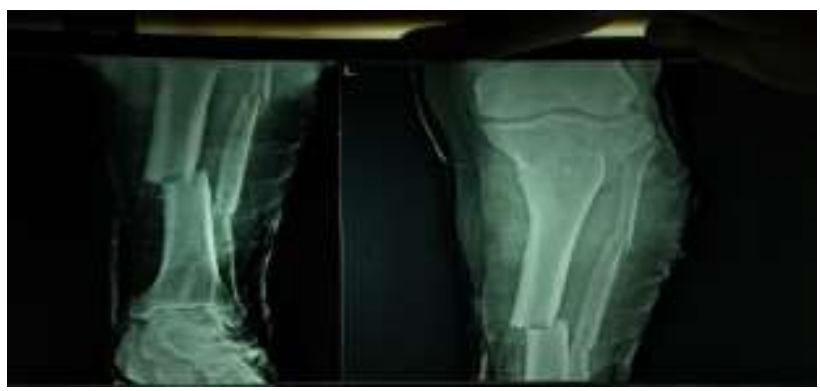

Figure 9: Segmental tibia fracture treated with hybrid external fixator.

\section{Case 10}

A 55 year male had type 3B open and type V schatzker fracture in RTA and achieved good results with union in 15 weeks. It required bone grafting and got pin tract infection.

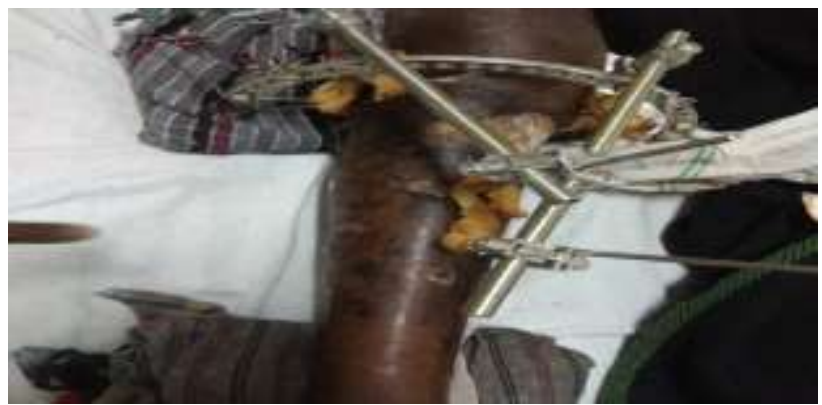

Figure 10: Proximal tibia fracture with poor skin condition fixed using fixator. 


\section{Case 11}

A 35 year male had close type III schatzker fracture in RTA and it united well in 12 weeks with good results and knee stiffness complication.

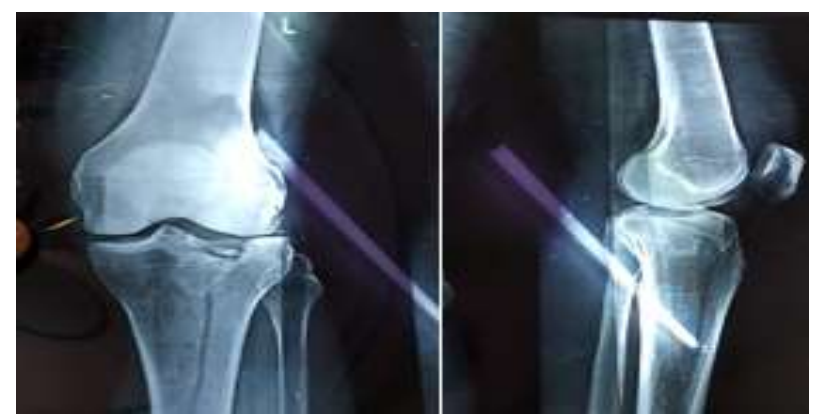

Figure 11: Depressed proximal tibia fracture managed with hybrid external fixator.

\section{Case 12}

A 45 year male with open type 3A and schatzker type VI fracture in RTA had united in 14 weeks with excellent results and superficial infection as complication.

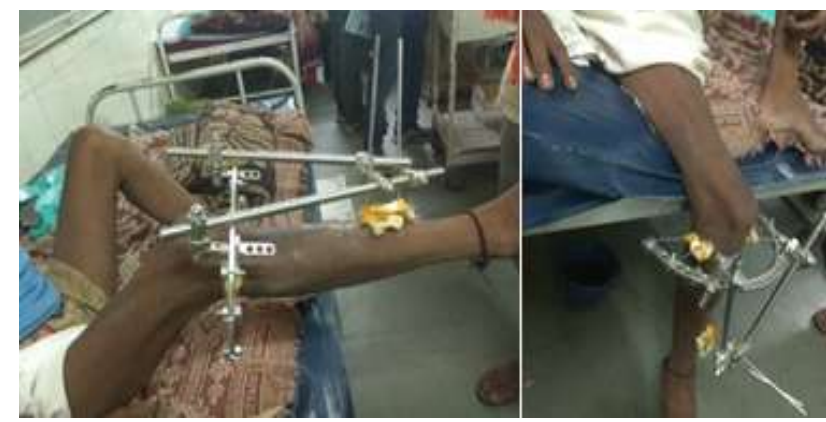

Figure 12: Type VI schatzker fracture fixed with hybrid fixator with good range of motion.

\section{Case 13}

A 30 year male had close, schatzker type I fracture due to fall on ground had excellent results with fracture union in 13 weeks.

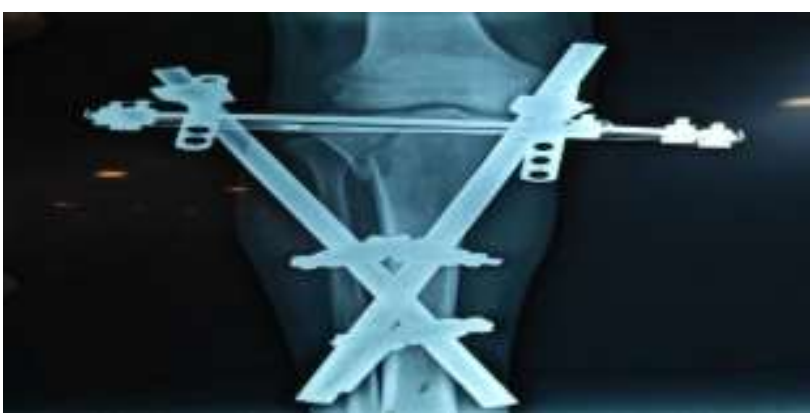

Figure 13: Split lateral condyle tibia fracture with hybrid fixator.

\section{Case 14}

A 55 year male had open type $3 \mathrm{~A}$ and schatzker type VI fracture in RTA had union achieved in 13 weeks with excellent results and superficial infection as complication.
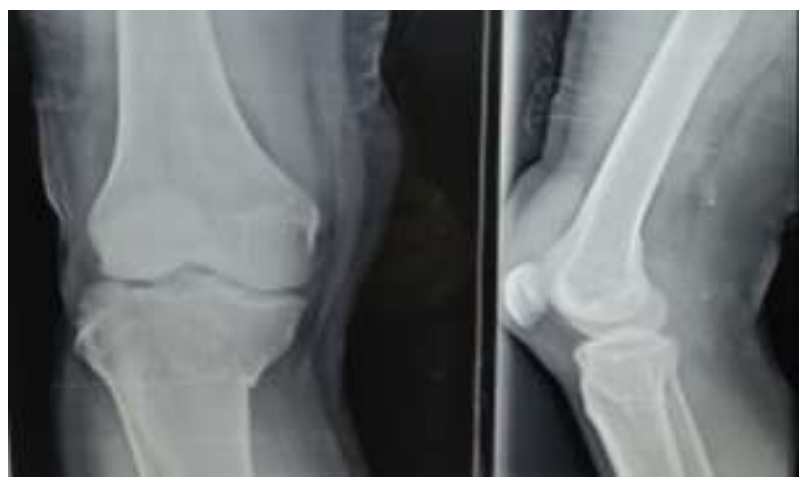

Figure 14: Schatzker type VI tibia fracture managed by fixator.

\section{Case 15}

A 21 year female had open type 3B and schatzker type V fracture in RTA and had union achieved in 15 weeks by bone grafting with good results and knee stiffness in complication.

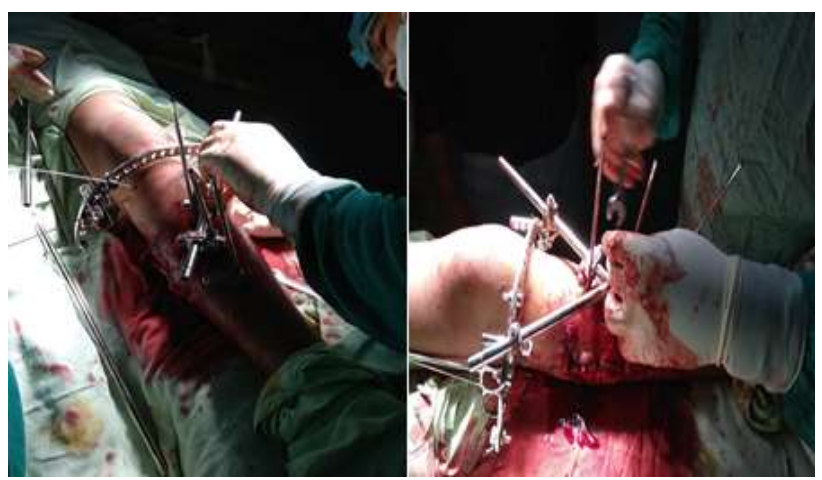

Figure 15: Open grade 3B proximal tibia fracture treated successfully with hybrid fixator.

\section{DISCUSSION}

Ever since the earliest documentable description of tibial plateau fractures, various treatment methods have evolved ranging from splinting, traction, cast bracing to open reduction and internal fixation, with each method having its merits and demerits. ${ }^{11}$

To overcome the demerits of both the operative and nonoperative philosophies and to combine the beneficial attributes of these, minimally invasive techniques are utilized. ${ }^{5,12}$ Minimal internal and hybrid external fixation method provides good stabilization and allows early range of motion for complex tibial plateau fractures where extensive dissection and internal fixation are 
contraindicated due to already precarious traumatized soft tissue and comminution of fracture. ${ }^{1,13}$

In our series maximum number of patients were in the age group 21-60 years $(93.32 \%)$ with mean age 42.8 years. Burri et al in a series of 278 cases cited average age of 44.8 years. ${ }^{14}$ Similarly, Lachiwicz et al evaluated 43 cases showing mean age of patients 42 years (range 16-70 years). ${ }^{4}$ Thus, we observed younger people sustaining this fracture more due to outdoor activities and active life.

In our case series out of 15 cases maximum patients were males $80 \%$ while females were $20 \%$ Lachiewicz et al observed almost equal frequency of both genders sustaining these fractures. ${ }^{4}$ Male predominance in our series and other studies indicate that number of male driving two wheeler and four wheeler are more as compared to female, thus there chance of sustaining fractures of tibial plateau are also more.

Road traffic accident was the most common mode of injury accounting for $80 \%$ of the cases; while fall from height was seen in $13.33 \%$ and assault was in only $6.66 \%$ of the cases. Rasmussen observed RTA as mode of injury in 55\% cases. ${ }^{15}$ In Burri et al observed RTA as a mode of injury in $55 \%$ cases and sport injury in $8.5 \%$ cases. ${ }^{14}$ In our series out of 15 cases maximum cases were of schatzker type V and type VI (53.33\%). Per se maximum cases of type V and type VI indicate more severe injury, involving high velocity trauma.

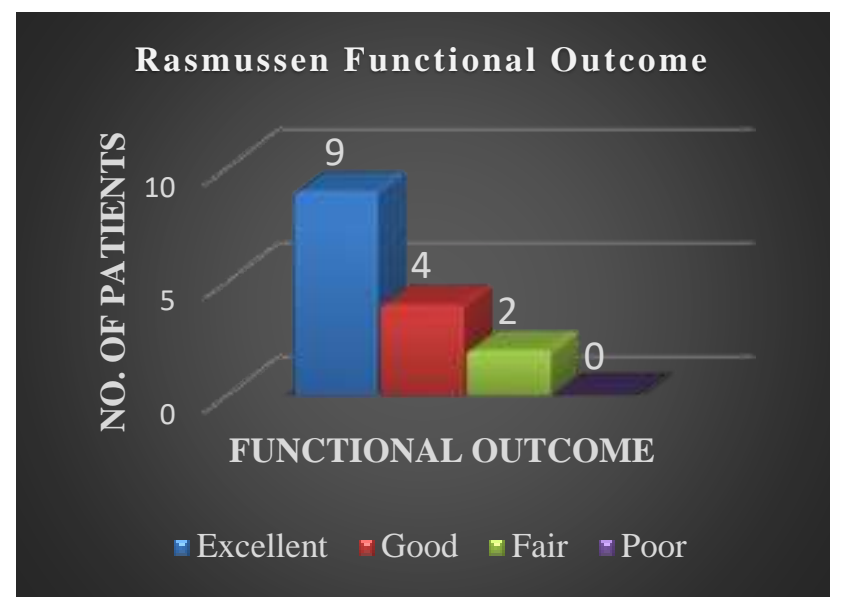

Figure 16: Rasmussen functional outcome.

Pain in knee was a common problem in 12 cases out of which 7 cases had occasional/cold weather pain, 5 had stabbing pain in certain position. However, the pain did not disturb the activities of daily living in majority of patients. Lachiewicz et al reported 20 out of 43 cases had knee pain. However, 3 cases had pain in activities of daily living. ${ }^{4}$

In our series out of 15 cases, $13(86.66 \%)$ had acceptable Rasmussen functional results (total of excellent and good results) with excellent in $9(60 \%)$, good in $4(26.66 \%)$, fair in $2(13.33 \%)$ cases (Figure 16). Kataria et al reported
Rasmussen functional results excellent in 19 , good in 17 and fair in 2 out of 38 cases. ${ }^{16}$ In our series Rasmussen radiological results were acceptable in 13 cases $(86.66 \%)$ consisting excellent in $9(60 \%)$, good in $4(26.66 \%)$, and fair in $2(13.33 \%)$ (Figure 17). Kataria et al observed Rasmussen radiological acceptable excellent in 6 , good in 26 , and fair in 6 out of 38 cases. $^{16}$

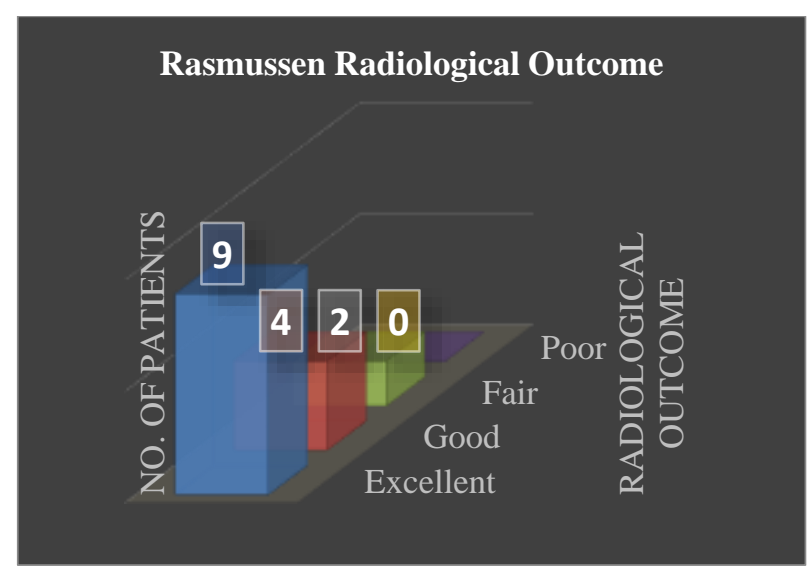

Figure 17: Rasmussen radiological outcome.

\section{CONCLUSION}

Minimal internal and hybrid external fixation for management of tibial plateau fracture with compromised soft tissue is more biological, requires less surgical time, less hospital stay, can be done in presence of compromised soft tissue, cost effective and have minimum complications with good functional outcome. From the observation of present study, it is concluded that stable, pain free, non-osteoarthritic knee with a functional range of motion should be the treatment goal for tibial plateau fracture with compromised soft tissue.

Funding: No funding sources

Conflict of interest: None declared

Ethical approval: Not required

\section{REFERENCES}

1. Dendrinos GK, Kontos S, Katsenis D, Dalas A. Treatment of high-energy tibial plateau fractures by the Ilizarov circular fixator. J Bone Joint Surg. 1996;78(5):710-7.

2. Stamer DT, Schenk R, Staggers B, Aurori K, Aurori B, Behrens FF. Bicondylar tibial plateau fractures treated with a hybrid ring external fixator: a preliminary study. J Orthop Trauma. 1994;8(6):45561.

3. Weiner LS, Kelley M, Yang E, Steuer J, Watnick N, Evans M, Bergman M. The use of combination internal fixation and hybrid external fixation in severe proximal tibia fractures. J Orthop Trauma. 1995;9(3):244-56.

4. Lachiewicz PF, Funcik T. Factors influencing the results of open reduction and internal fixation of 
tibial plateau fractures. Clin Orthop Relat Res.1990;259:210-5.

5. Duwelius PJ, Rangitsch MR, Colville MR, Woll ST. Treatment of tibial plateau fractures by limited internal fixation. Clin Orthop Relat Res. 1997;339:47-57.

6. Cross AR, Lewis DD, Murphy ST, Rigaud S, Madison JB, Kehoe MM, Rapoff AJ. Effects of ring diameter and wire tension on the axial biomechanics of four-ring circular external skeletal fixator constructs. Am J Vet Res. 2001;62(7):1025-30.

7. Gossling HR, Peterson CA. A new surgical approach in the treatment of depressed lateral condylar fractures of the tibia. Clin Orthop Relat Res. 1979;140:96-102.

8. DeCoster TA, Crawford MK, Kraut MA. Safe extracapsular placement of proximal tibia transfixation pins. J Orthop Trauma. 1999;13(4):23640.

9. Su EP, Westrich GH, Rana AJ, Kapoor K, Helfet DL. Operative treatment of tibial plateau fractures in patients older than 55 years. Clin Orthop Relat Res. 2004;421:240-8.

10. Geller J, Tornetta III P, Tiburzi D, Kummer F, Koval $K$. Tension wire position for hybrid external fixation of the proximal tibia. J Orthop Trauma. 2000;14(7):502-4.
11. Papagelopoulos PJ, Partsinevelos AA, Themistocleous GS, Mavrogenis AF, Korres DS, Soucacos PN. Complications after tibia plateau fracture surgery. Injury. 2006;37(6):475-84.

12. Gausewitz ST, Hohl MA. The significance of early motion in the treatment of tibial plateau fractures. Clin Orthop Relat Res. 1986;202:135-8.

13. Gaudinez RF, Mallik AR, Szporn M. Hybrid external fixation of comminuted tibial plateau fractures. Clin Orthop Relat Res.1996;328:203-10.

14. Burri C, Bartzke G, Coldewey J, Muggler E. Fractures of the tibial plateau. Clin Orthop Relat Res.1979;138:84-93.

15. Rasmussen PS. Tibial condylar fractures: impairment of knee joint stability as an indication for surgical treatment. JBJS. 1973;55(7):1331-50.

16. Kataria H, Sharma N, Kanojia RK. Small wire external fixation for high-energy tibial plateau fractures. J Orthop Surg. 2007;15(2):137-43.

Cite this article as: Sharma MK, Jain M, Jain HK, Khichar S, Jadoo R. Management of tibial plateau fractures with compromised soft tissue using hybrid external fixator. Int J Res Orthop 2020;6:1297-302. 